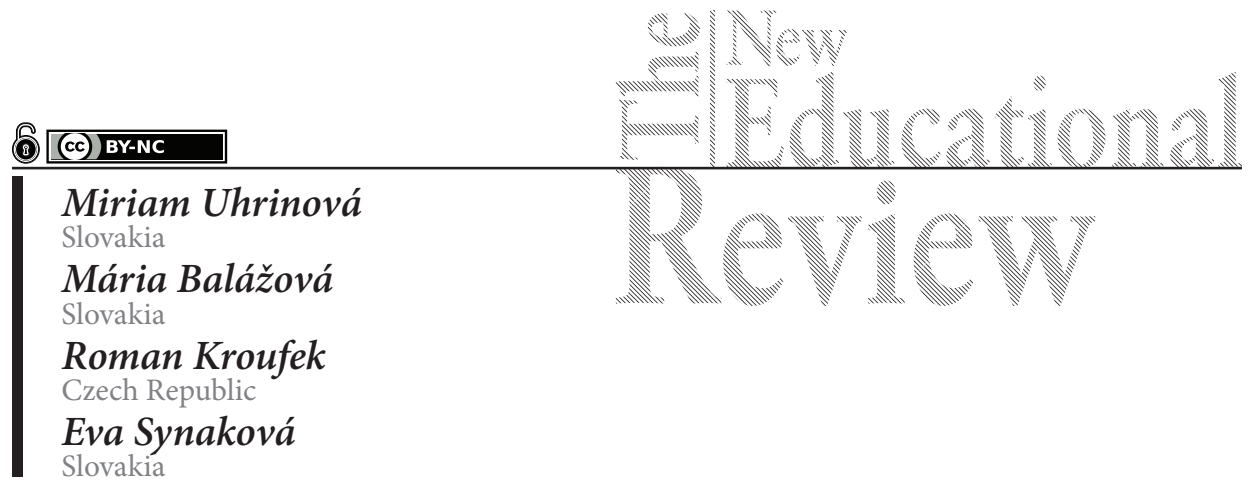

\title{
Selected Aspects of Environmental Literacy Among Pupils with Regard to the Aims of Primary Education
}

DOI: $10.15804 /$ tner.2021.66.4.05

\begin{abstract}
Considering the current conditions in environmental education and training in Europe and the world, it is essential to put emphasis on the increase of the environmental literacy of pupils in the educational environment. The paper presents findings of the conducted research focused on the regional identity in relation to environmental literacy of pupils. The empirical research was of a quantitative-qualitative character. The subject of the research was the level of environmental literacy of pupils of primary education and selected aspects in its development in educational process. The research was conducted in 630 schools from all over Slovakia. In the paper we focus mainly on the findings obtained from questionnaires completed by primary education pupils and from interviews carried out by teachers. The research findings highlight the need of pupils for direct contact with nature with regard to the improvement of their level of environmental literacy.
\end{abstract}

Key words: environmental literacy, education, primary school, pupil, Slovakia 


\section{Introduction}

In the current period of unexpected changes (such as the COVID-19 pandemic and its variants), new needs and educational requirements are suddenly emerging. Educational processes face unforeseen challenges where it is necessary to counterbalance the emergent negatives and impacts of the current era and seek effective ways to eliminate them. Considering the current needs and trends in environmental education and training in Europe and worldwide, it is essential to make effective use of the educational space and to put emphasis on the increase of the environmental literacy of pupils. Environmental literacy can be seen as a complex of the following dimensions: knowledge (cognitive dimensions), dispositions (affective dimensions), competences and environmentally responsible behaviour (action dimensions). It is essential to develop students' environmental literacy not only in the cognitive dimensions, but also in the action and affective dimension.

Considering the regional context in primary education, the relationship of younger school-age children to their environment is strengthened through exploring the region by going to the countryside and getting attached to nature, which has a positive impact on their level of environmental literacy. It has been shown that people tend to protect places that are significant to them, which is consistent with the research finding of Manzo and Perkins (2006). Several empirical studies show that the attachment to the place is strengthened by frequent visits and the use of places (Ryan 2005). This needs to be exploited in the educational process as well. Environmental education could improve pupils' awareness and appropriate behaviour towards nature (Rindaningsih et al., 2020).

It is precisely society that has been burdened by the impact of the recent period, especially by the increase of waste (disposable plastic packaging, masks, etc.) and pupils need to be directed towards the implementation of activities that lead to the sustainable development of the region. It is equally important to compensate for their lack of exercise during the pandemic situation. It is the natural environment that provides a suitable setting in which they gain experience, skills and opportunities to spend time in the fresh air. At the same time, they form an attachment to nature and a relationship to the natural world, which influence their pro-environmental behaviour towards nature. This process, according to Mack et al. (2013) should be applied non-violently and focused on the specific conditions of a person's environment. As stated by Křepelková et al. (2020), pro-environmental behaviour is the key to the protection and sustainability of the environment. It is important to know which variables influence the level of pro-environmental 
behaviour and how important is the direct interaction of pupils with the nature for future environmental engagement with regard to sustainable development.

\section{Research Focus}

If we embrace the multidimensional approach to environmental literacy of the North American Association for Environmental Education (Hollweg et al., 2011), a frequent target of researchers is its affective dimension, called disposition. Within this dimension, research mostly focuses on approach to the environment (Dunlap, 2008), control orientation (Hines et al., 1987), and sensitivity to the environment (Chawla, 1998). Environmental sensitivity can be broadly identified with an individual's approach to the nature. It represents an important area of research and is the centre of growing professional interest (Restall \& Condrad, 2015). Understanding of one's relationship to nature and the ability to measure it can serve as an interesting source for assessing the level of environmental literacy (Liefländer et al., 2013). Several authors have shown in their subsequent studies that the construct of relatedness to nature is a predictor of a person's mental well-being (Nisbet et al., 2011). Research has also shown the impact of spending time in nature on an individual's nature-responsible behavior (Dutcher, D. et al., 2007, Zelenski et al., 2015, Whitburn et al., 2019). The teacher plays an important role in the educational space in developing positive relationship of students to nature. Kubiatko at al. (2021) state that in order for children to develop a positive relationship to nature, their educators need to have a like-minded personal quality. According to Mack et al. teachers effectively contribute to the development of students' environmental literacy (2012), if new educational models are applied in this era. Nowadays, we can also consider play as one of the proven methods of the educational process in pre-primary and primary education with regard to environmental education (Vargova et al., 2021). It can also be used in the context of the concept of gamification. In the educational space, it is necessary to look for precisely activating methods and strategies that would motivate pupils to spend time in nature and to have direct contact with nature.

In Slovakia, there is a lack of research that would representatively show the results focused on variables that have an impact on increasing the level of environmental literacy of pupils with regard to spending time in nature and interconnection with nature.

The relationship of children to nature, which also influences their pro-environmental behaviour, changes with the age and is influenced by different factors. The aim of this paper is to present the results of the research aimed at finding out 
the level of environmental literacy of primary school pupils with regard to their relationship to nature.

\section{Methodology of Research}

\section{General Background of Research}

The empirical research was quantitative-qualitative in nature. The subject of the research was the level of environmental literacy of pupils of primary education and certain aspects of its development in the educational process. In this paper we want to focus on the presentation of the results of the research, which aimed to determine the level of environmental literacy of pupils of the $4^{\text {th }}$ grade of primary schools in Slovakia and to map the present state of the existing environmental education at the first level of primary schools. Within the level of environmental literacy, we focused on the area of competence - relationship to nature. Within this area, we focused on the need of pupils' contact with nature. We investigated whether the level of environmental literacy in pupils can be changed by interventions such as the frequency of visits to nature, the perceived need for contact with nature and the interconnection with nature.

We based our research questions on the following:

- How does the frequency of nature visits affect the level of selected aspects of students' environmental literacy?

- How does the perceived need for contact with nature affect the level of selected aspects of pupils' environmental literacy?

- Does gender affect the level of selected aspects of pupils' environmental literacy?

- What space is currently dedicated to environmental education in the educational process in primary education and what didactic strategies are used for its implementation?

\section{Sample of Research}

The research project was carried out between February and June 2021. A total number of 630 primary schools in Slovakia were selected for the research. In the research, opportunity and quota sampling was applied. 1182 pupils participated in the research, 618 girls and 564 boys. The sample is made up of pupils of the $4^{\text {th }}$ grade of randomly selected schools that were willing to involve their pupils in the research. The participants of the study were sixteen $4^{\text {th }}$ grade primary school teachers who were randomly selected. Due to anti-pandemic measures, the meet- 
ing with teachers was limited and the research was thus narrowed down from the original planned number of respondents.

\section{Instrument and Procedures}

Environmental questionnaire method and interview method were used as the primary methods in the empirical research. We used a questionnaire addressed to students and interviews with teachers. In the research we used a questionnaire that was compiled on the basis of the Methodology for the evaluation of environmental education for pre-school and younger school age (Činčera, 2013), which summarizes questionnaires for identifying the level of environmental literacy of pupils by several foreign authors (Cheng \& Monroe, 2012; Beery, 2013, etc.). To determine the level of environmental literacy, we created a questionnaire in which we used a five-point Likert scale with modified items from the questionnaire for measuring the frequency of visits to nature, detecting the perceived need of pupils to be in contact with nature and measuring the level of interconnection of $4^{\text {th }}$ grade primary school pupils with nature.

To collect responses from teachers, we used structured interviews. We used the same interview questions in the unchanged order. We investigated the opinions of teachers on what space is now devoted to environmental education and what strategies and methods are most often used for this core theme in the educational process.

\section{Data Analysis}

To process and analyse the results from the questionnaire, we used the mathematical-statistical operations of absolute and relative abundance. Comparison of the results between the categories depending on the hypotheses stated was made by ANOVA. To identify the difference between boys and girls based on all the questions of the questionnaire, we used Discriminant Analysis. Statistical processing of the results was done in STATISTICA 8 (Statsoft). To process the results from the interviews, we used the method of qualitative analysis of the responses. We analysed the teachers' responses, focusing on the content and the essential meaning of the answers.

\section{Results of Research}

One of the objectives of the research was to investigate how the frequency of nature visits affects the level of selected aspects of students' environmental literacy, 
focusing on affective and conative components. There was a statistically significant effect ( $\mathrm{p}=0.0000)$ of the implementation of pupils' visits to nature on the identified values of selected aspects of environmental literacy. Pupils who made more visits to nature in the last 14 days achieved higher values of the interconnection to nature than pupils who made fewer visits to nature (Fig. 1).

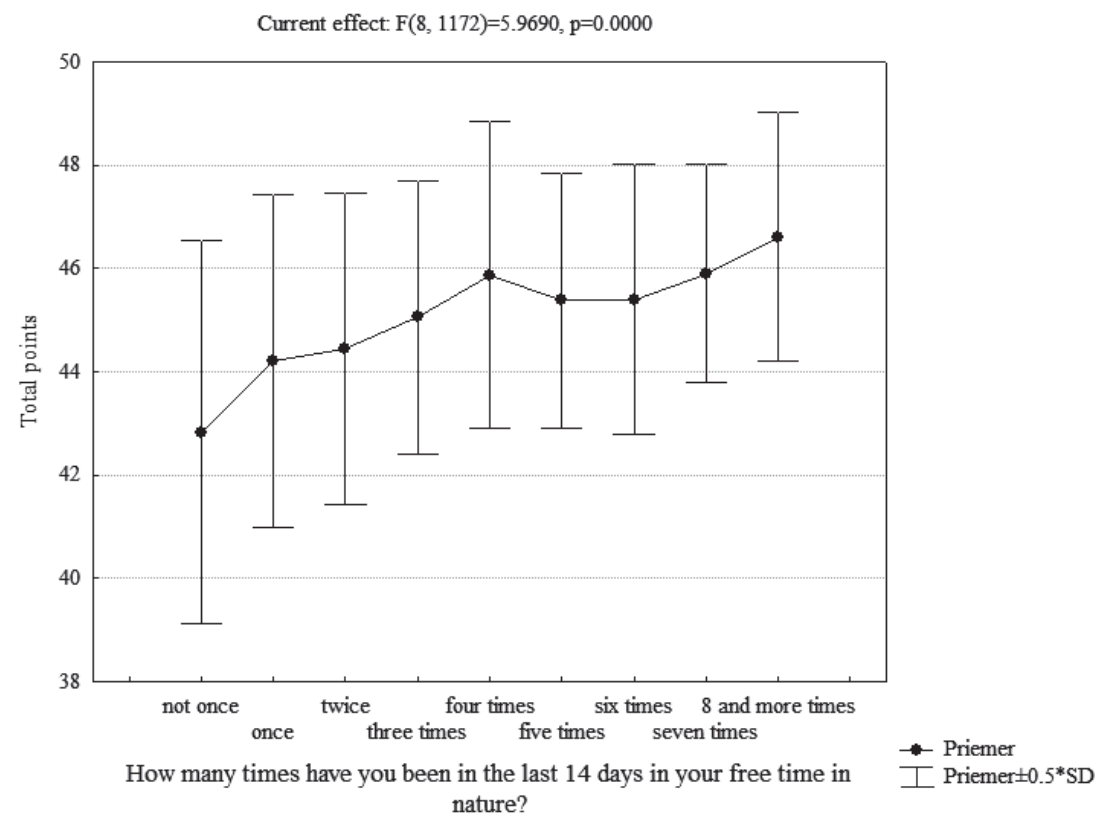

Figure 1. The impact of the frequency of visits to nature on the interconnection with nature

We were further interested in whether pupils who feel a greater need to be interconnected to nature will also have higher levels of environmental literacy. Significantly higher values in the variable interconnectedness to nature were obtained by pupils who have a higher level of perceived need for contact with nature ( $\mathrm{P}=0.0000$, Fig. 2 ). As the level of perceived need for contact with nature increases, the level of interconnectivity of pupils with nature also goes up. Pupils who have low interconnectedness to nature would even welcome it if their visits to nature were more reduced.

One interesting finding is the correlation between perceived need of pupils for contact with nature and the satisfaction with how often pupils are in nature. In this case, pupils who want to go to nature as often as they go statistically achieved 


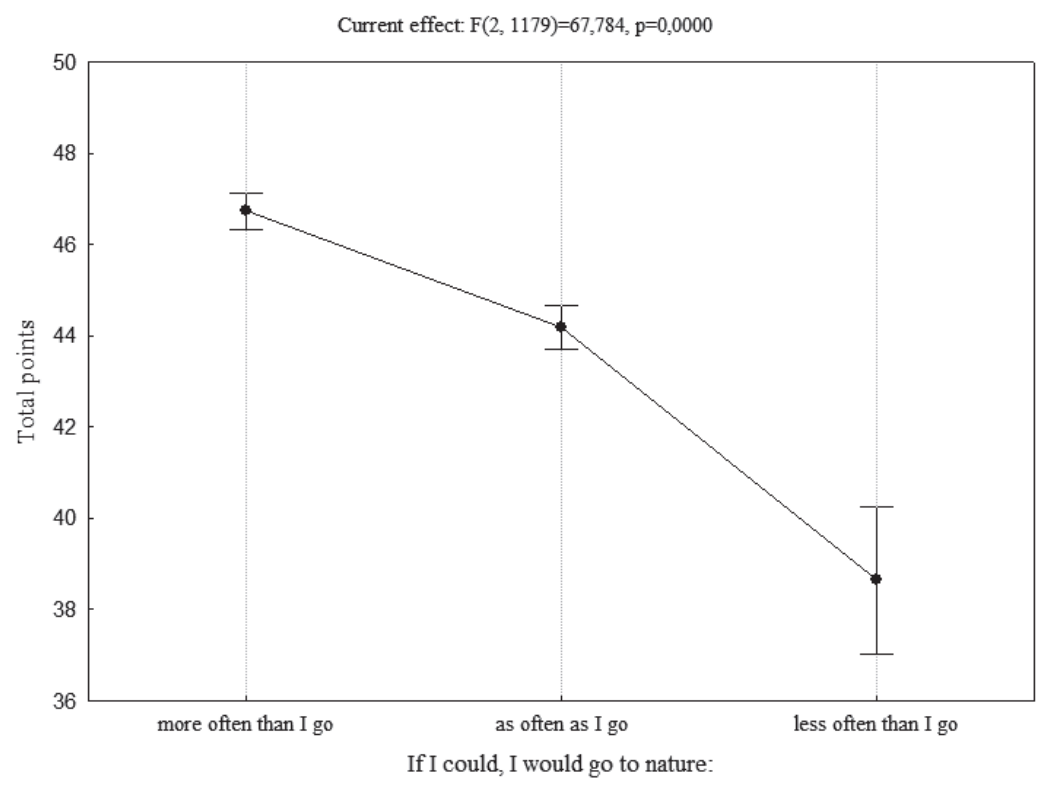

Figure 2. Correlation of perceived need for contact with nature and interconnectedness to nature

the highest level of satisfaction with the frequency of visits to nature (Table 1). At the same time, it was confirmed that those who visit the nature little would like to go even less.

Table 1. Differences in perceived need for contact with nature and satisfaction depending on frequency of visits to nature

\begin{tabular}{|c|c|c|c|}
\hline & \multicolumn{3}{|c|}{$\begin{array}{l}\text { How satisfied are you with the frequency you are in the } \\
\text { nature? }\end{array}$} \\
\hline & $\mathrm{N}$ & Mean & Std.Dev. \\
\hline more often than I go & 671 & 5,5 & 1,61 \\
\hline as often as I go & 469 & 5,9 & 1,26 \\
\hline less often than I go & 42 & 3,9 & 1,87 \\
\hline
\end{tabular}

When investigating the differences between boys and girls in interconnectedness to nature, we also found significant differences ( $p=0.0000$, Fig. 3). Girls scored higher in interconnectedness to nature than their male classmates. Using 


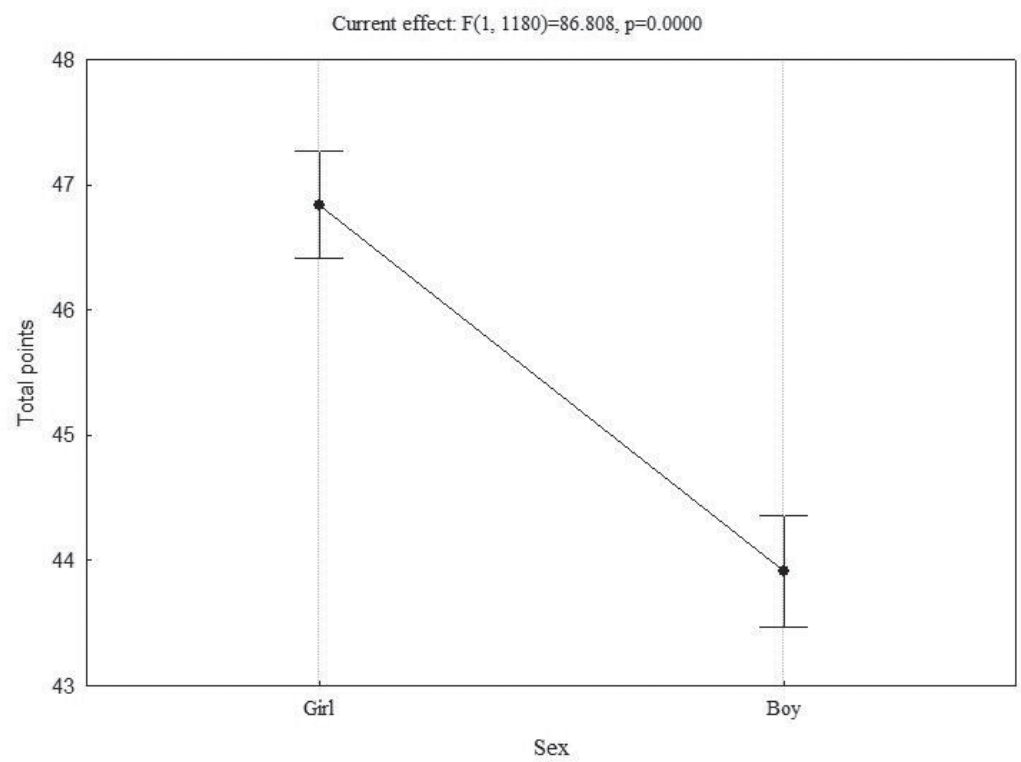

Figure 3. Correlation of interconnectedness to nature and gender of pupils

discriminant analysis, we determined that the variables (questionnaire questions, e.g. the attitude towards working in the garden, observing flowers in bloom..., Tab. 2) in which the attitudes of boys and girls differ most (and significantly) are primarily related to observing flowers and animals, collecting shells and pebbles, or working in the garden. The variables are quantitative assessments of feelings, attitudes, and approach to nature from different perspectives (Tab. 2).

Table 2. Variables significantly influencing (in bold) differences in interconnectedness to nature and gender of pupils

\begin{tabular}{lcc}
\hline \multicolumn{1}{c}{$\begin{array}{c}\text { Discriminant Function Analysis Summary F (13,1168)=13,260 } \\
\mathrm{p}<0,0000\end{array}$} & F-remove & p-level \\
\hline 1. Attitude towards listening to different sounds in nature & 1,8542 & 0,1736 \\
\hline 2. Attitude towards observing wild flowers & $\mathbf{5 7 , 5 2 7 8}$ & $\mathbf{0 , 0 0 0 0}$ \\
\hline 3. Attitude towards going to nature in times of sadness & $\mathbf{2 0 , 8 4 3 6}$ & $\mathbf{0 , 0 0 0 0}$ \\
\hline 4. Attitude towards working in the garden & $\mathbf{4 , 2 8 4 9}$ & $\mathbf{0 , 0 3 8 7}$ \\
\hline 5. Feelings from collecting stones and shells & $\mathbf{1 8 , 0 2 4 9}$ & $\mathbf{0 , 0 0 0 0}$ \\
\hline 6. Feelings from being outdoors & 0,6621 & 0,4160 \\
\hline
\end{tabular}




\begin{tabular}{lcc}
\hline 7. Feelings when harming animals & 0,4113 & 0,5214 \\
\hline 8. Attitude towards observing wild animals in a healthy environment & 5,2705 & $\mathbf{0 , 0 2 1 9}$ \\
\hline 9. Feelings when touching animals and plants & 3,0001 & 0,0835 \\
\hline 10. Personal relationship in caring for animals & 2,7242 & 0,0991 \\
\hline 11. Attitude towards life without plants and animals & 2,9623 & 0,0855 \\
\hline 12. Attitude towards doing something for nature & 0,0138 & 0,9066 \\
\hline 13. Attitude towards picking up litter in nature & 1,0173 & 0,3134 \\
\hline
\end{tabular}

Our research findings were complemented by the results of interviews with teachers who teach pupils at the first level of primary school.

From the perspective of teachers, we concluded the following key findings based on the analysis from the interviews in relation to the stated research questions:

- Teachers try to incorporate environmental education quite often, usually at least once a week. They also integrate environmental education during breaks when they are outside in the schoolyard. At one school they have set up eco-patrols to supervise waste separation within each classroom.

- With the environmental topics in the educational process, teachers most often use the interview and discussion method. However, they try to use activating methods and concepts in environmental education. When implementing environmental education, they use cooperative teaching, project-based learning, integrated thematic teaching, problem-based learning, brainstorming and discovery methods. Several teachers also use ICT, such as videos, in which they can see a global problem in specific terms and start to think more about it.

- More than half of the teachers prefer methods in which pupils learn directly in nature, where they can touch and feel the nature.

- Several teachers agreed that anything that pupils can try, discover, play, feel, think, create with their own hands and thinking, will leave them with a memory, an experience and consequently with better remembering.

The interview also indicated the problem of the deficit of space for the implementation of environmental education today, which is marked by the pandemic situation associated with the Covid-19. More than a half of the teachers perceive the pandemic and the related measures as a negative impact on the teaching of environmental education. The most common problem is that they do not have enough time for cross-curricular subjects due to catching up in subjects such as Slovak language and mathematics. Teachers regard distance education as another major problem, where teachers do not have the opportunity to bring pupils into direct contact with nature. However, one teacher was able to take advantage even 
of this situation in favour of environmental education and started to teach several lessons outdoors with pupils on the school grounds. For example, she had never taught music education outdoors before, but now she finds it ideal. When the pupils cannot sing (due to pandemic measures) indoors, they go to listen to the sounds of the forest and the sounds of nature, which provides great opportunities for environmental education. Regarding all school events, it has not been possible to implement them as mass events are not preferred at the moment.

\section{Discussion}

Based on the conducted research, we found that pupils' relationship to nature also influences their environmental behaviour. Pupils who are interconnected to nature also have a need to protect and care for it. At the same time, their level of environmental literacy increases, especially in the affective and conative domains.

We were interested in how the frequency of visits to nature affects the level of selected aspects of environmental literacy of pupils. We concluded that the frequency of nature visits by pupils positively influences the level of their interconnectedness to nature, which is one of the aspects of environmental literacy. According to our research, pupils who make frequent visits to nature achieved significantly higher values of interconnectedness to nature than those who make visits less frequently or do not make visits to nature not at all.

We investigated how the perceived need for contact with nature influences the level of selected aspects of environmental literacy of pupils. The results of the research confirmed that pupils who felt a greater need for contact with nature scored higher on interconnectedness to nature than those who felt little or no such need. This means that pupils who are more interconnected to nature also feel a greater need to spend more time in nature. There was an intercorrelation between the felt need for contact with nature and interconnectedness to nature.

Interaction with nature in childhood influences future pro-environmental behaviour. This fact has been confirmed by the results of several studies (Křepelková et al., 2020). However, we were interested in whether the gender of pupils of younger school age influences the level of selected aspects of pupils' environmental literacy. Our research shows that girls demonstrate higher levels of interconnectedness to nature than boys. Thus, gender is among the variables that influence the level of selected aspects of pupils' environmental literacy. In this context, it would be interesting to identify differences in the cognitive, affective and conative dimensions of the level of environmental literacy. We have surveyed 
selected aspects with regard to affective and conative components. Generally, girls are more sensitive in this respect, which was reflected in their relationship to nature, and this aspect may have influenced the results of the research in favour of girls.

In the context of the addressed issue, environmental literacy can be promoted and its level increased by effective implementation of environmental education in the educational process. Within the framework of the research, we also sought answers to the question of what space is now devoted to environmental education in the educational process in primary education and what didactic strategies are used for its implementation. In this regard, it is encouraging that teachers prefer activating methods in the implementation of environmental education in the context of primary education. In the interview, it was mentioned mainly cooperative teaching, project-based learning, integrated thematic teaching, problem-based learning, brainstorming and discovery methods. Teachers also include ICT work in their schools. Experiential pedagogy has been identified as a very proven concept suitable for environmental education. However, a difficulty emerged with distance learning, which was implemented during the pandemic situation caused by the Covid-19. Teachers did not have sufficient space to implement environmental education. In this regard, it proves important to motivate pupils, but also their parents, to interact more with nature in their free time. The assignment of various educational tasks could also be directed, which can also be carried out outdoors, near their home. In this regard, we did not identify educational tendencies among teachers in the context of possible further distance education in schools, which could be the subject of our further research.

\section{Conclusions}

One of the most important topics in environmental education research is the interconnection between students and nature. The conducted research points to the need to educate pupils in the environmental area, especially with regard to the affective and conative dimensions.

Based on the results of the research, it can be concluded that the frequency of visits and pupils' interest in being in contact with nature are related to their interconnectedness to nature. Our research findings show that pupils' relationship to nature also influences their pro-environmental behaviour. Teachers play a significant role in creating a positive relationship to nature in the educational space of primary education. In fact, environmental education and its effective imple- 
mentation in the educational process is also in their competence. This is required already in children of younger school age with regard to the improvement of their level of environmental literacy. Children at this age need professional guidance in order to develop their competences through experiences or by building a positive attitude towards nature through direct contact with nature.

Since the level of selected aspects of environmental literacy is directly proportional to the amount of time pupils spend in nature, we recommend that teachers should visit nature with pupils as part of the educational process, so that pupils have a direct contact with nature. It is advisable to hold lessons directly in nature, for example on the school grounds, in a meadow or in the woods. We would recommend frequent walks in the countryside. When meeting with parents, it is advisable to encourage them to go outdoors with their children and to encourage their children to spend as much time outdoors as possible. Outdoor learning also provides a great deal of inspiration for environmental education, which can make it much easier for teachers to integrate this cross-curricular subject into the education process. We recommend that teachers use elements of experiential pedagogy and activating methods and concepts such as discovery methods, cooperative learning, integrated thematic teaching, project-based learning and problem-based learning in environmental education. These methods and concepts make it possible to shape and influence pupils' views and attitudes towards nature and the environment. In addition, pupils will learn more naturally and remember more. We recommend that primary schools include after-school clubs in their extra-curricular activities, during which pupils can spend time in nature and which will encourage them to behave in a pro-environmental way. In this way, it is possible to fill the free time of pupils in a meaningful way and to guide them towards love of nature and the environment.

\section{Acknowledgements}

This article was supported by Catholic University in Ružomberok as a grant VEGA No. 1/0624/20: Regional identity as a cooperative factor of environmental literacy development in primary schools.

\section{References}

Beery, T.H. (2013). Establishing reliability and construct validity for an instrument to measure environmental connectedness. Environmental Education Research, 19(1), 81-93. Činčera, J. (2013). Metodika pro hodnocení environmentální výchovy pro předškolní 
a mladší školní věk/ Methodology for the evaluation of environmental education for preschool and early school age. Envigogika, 8(5). DOI: http://dx.doi.org/10.14712/18023061.

Dunlap, R.E. (2008). The New environmental paradigm scale: From marginality to worldwide use. The Journal of Environmental Education, 40 (1), 3-18.

Dutcher, D., Finley, J., Luloff, A., Johnson, J. (2007). Connectivity with nature as a measure of environmental values. Environment and Behavior, 39, 474-493.

Hines, J.M., Hungerford, H.R., \& Tomera, A.N. (1987). Analysis and synthesis of research and responsible environmental behavior: A meta-analysis. Journal of Environmental Education, 18 (2), 1-8.

Hollweg, K.S. Taylor, J.R., Bybee, R.W., Marcinkowski, T.J., McBeth, W.C., \& Zoido, P. (2011). Developing a Framework for Assessing Environmental Literacy. Washington, DC: North American Association for Environmental Education.

Chawla, L. (1998). Significant Life Experiences Revisited: a review of research on sources of environmental sensitivity. Environmental Education Research, 4 (4), 369-382.

Křepelková, Š., Krajhanzl, J., \& Kroufek, R. (2020). The influence of interaction with nature in childhood on future proenvironmental behavior. Journal of Baltic Science Education, 19(4), p. 536-550. https://doi.org/10.33225/jbse/20.19.536

Kubiatko, M., Nepras, K., Strejckova, T., \& Kroufek, R. (2021). On wolves and bees: Which factors influence the nature relatedness of the pre-service teachers. Journal of Baltic Science Education, 20(2), 252-260. https://doi.org/10.33225/jbse/21.20.252

Liefländer, A.K., Fröhlich, G., Bogner, F.X., \& Schultz, P.W. (2013) Promoting connectedness with nature through environmental education. Environmental Education Research, 19(3), 370-384.

Macko, J., Blahútová, D. \& Stollárová, N. (2012). New Education Model for Information Monitoring of Environment Water Flows. Informatologia, 45(3) 232-237.

Macko, J., Blahútová, D., Stollárová, N. (2013). Space for the environmental education in the system of secondary education in Slovakia. Informatologia, 46(3), 256-260.

Manzo, L.C., Perkins, D.D. (2006). Neighborhoods as Common Ground: The Importance of Place Attachment to Community Participation and Development. Journal of Planning Literature, 20, 335-350.

Nisbet, E.K., Zelenski, J.M., \& Murphy, S.A. (2011). Happiness is in our Nature: Exploring Nature Relatedness as a Contributor to Subjective Well-Being. Journal of Happiness Studies, 12(2), 303-322.

Rindaningsih, I., Setyosari, P., Kuswandi, D., \& Ulfa, S. (2020). Development of Seamless Learning to Facilitate Formal and Informal Learning in Elementary Education. The New Educational Review, 61(3), 51-62. DOI:10.15804/tner.2020.61.3.04.

Restall, B., \& Condrad, E. (2015). A literature review of connectedness to nature and its potential for environmental management. Journal of Environmental Management, 159, 264-278.

Ryan, R.L. (2005). Exploring the effects of environmental experience on attachment to urban natural areas. In Environment and Behavior, 37(1), 3-42.

Vargová, M., Anna Klim-Klimaszewska, A. (2021). Through the Diversity of Children's 
Game to the Subsequent Learning. The New Educational Review, 65(3), 165-177. DOI:10.15804/tner.2021.65.3.13.

Whitburn, J., Linklater, W.L., \& Milfont, T.L. (2019). Exposure to urban nature and tree planting are related to pro-environmental behavior via connection to nature, the use of nature for psychological restoration, and environmental attitudes. Environment and Behavior, 51(7), 787-810. https://doi.org/10.1177/0013916517751009

Zelenski, J.M., Dopko, R.L., \& Capaldi, C.A. (2015). Cooperation is in our nature: Nature exposure may promote cooperative and environmentally sustainable behavior. Journal of Environmental Psychology, 42, 24-31. https://doi.org/10.1016/j.jenvp.2015.01.005 